\title{
Handicap one year after a stroke: validity of a new
}

\author{
scale
}

\author{
Rowan H Harwood, Patrick Gompertz, Shah Ebrahim
}

\begin{abstract}
The aim was to determine the handicap experienced by subjects one year after a stroke, and assess the acceptability, validity, and reliability of a new handicap measurement scale.

A cross sectional survey of 141 survivors of a cohort of consecutive hospital admissions with acute stroke was undertaken. The London handicap scale (a new health outcome measurement scale), Barthel index, Nottingham extended activities of daily living scale, Nottingham health profile, Geriatric depression score, and a global life satisfaction scale were used. 94 subjects $(67 \%)$ responded to a single mailing; 89 (95\%) responses were usable. Mean handicap was 0.40 (range $0.06-1 \cdot 0$, SD $0 \cdot 20$ ) on a scale of 0 (maximum handicap) to 1 (no handicap). All handicap dimensions showed a wide range of problems, with physical independence and occupation particularly affected. Correlations between handicap score and other outcome measures were all in the expected direction and of about the strength expected $(0.36<r<0.69)$. The reliability coefficient was $0 \cdot 91$, limits of agreement $\pm 0 \cdot 19$. The measurements demonstrated substantial handicap one year after a stroke, reflecting considerable unmet rehabilitation needs. The scale proved acceptable to subjects, and the results were consistent with good validity.
\end{abstract}

(F Neurol Neurosurg Psychiatry 1994;57:825-829)

The London handicap scale was developed in response to the need for measures of morbidity to complement mortality statistics as outcomes in evaluating health care interventions and services. Handicap is the disadvantage experienced by an individual patient because of ill health, due to the inability to perform a role that is normal for someone of the same age, sex, and background. ${ }^{1}$ Reducing handicap is the aim of rehabilitation, and is central to the management of elderly people, and others with multiple, chronic, irreversible or progressive diseases. ${ }^{2}$ The concept is closely defined, relevant, limited to the context of health experience (while taking due account of important non-health factors such as wealth, relationships, and physical environment), and is closely related to the idea of quality of life.
Handicap can be classified according to disadvantages in each of six dimensions: mobility, physical independence, occupation, social integration, and economic self sufficiency. ${ }^{1}$ More complex roles can generally be described in terms of these dimensions. The London handicap scale comprises a classification questionnaire and a matrix of scale weights. The classification questionnaire has six questions, one for each dimension, each comprising a six point hierarchical scale of disadvantages in a self completion format, although the descriptions are objective enough for completion by a carer or other informant if necessary. The matrix of scale weights enables the severity of disadvantage in each dimension to be combined in an overall handicap score, ranging from 1 (no handicap) to 0 (maximum handicap). The weights were derived in interviews with 79 randomly selected, community dwelling subjects, and analysed according to a market research technique called conjoint analysis (personal communication). ${ }^{34}$

To assess the acceptability, construct validity, and reliability of the scale, a sample of stroke patients were studied, and comparisons made with other outcome measures. We tested the hypotheses that handicap would be greater in those with greater disability on the Barthel index ${ }^{5}$ and Nottingham extended activities of daily living (ADL) scale, ${ }^{6}$ those with worse perceived health state on the Nottingham health profile (NHP) parts 1 and $2,{ }^{7}$ who were more depressed on the Geriatric depression score, ${ }^{89}$ and those with worse satisfaction with life on a seven point ordinal faces scale. ${ }^{10}$

Stroke is a common condition, an important cause of long term disability, ${ }^{11}$ and responsible for about $5 \%$ of NHS expenditure and $10 \%$ of NHS bed days. The wider impact of stroke has been relatively little studied. ${ }^{12}$

\section{Method}

Three hundred and sixty one subjects admitted to hospital with acute stroke in two adjacent east London health districts were identified by twice weekly ward visits. Their outcomes at 12 months were determined by a postal questionnaire comprising measures of disability, mood, perceived health, and life satisfaction. Non-responders were sent further reminders or were telephoned or visited at home to provide help with completion.

Subjects on whom outcome measurements had been completed were sent a copy of the 
Table 1 Characteristics of subjects completing handicap questionnaire, and registered 12 month survivors who did not (means unless stated)

\begin{tabular}{|c|c|c|c|}
\hline & $\begin{array}{l}\text { Handicap score } \\
\text { measured }(n=89)\end{array}$ & $\begin{array}{l}\text { No handicap } \\
\text { score }\end{array}$ & (n) \\
\hline 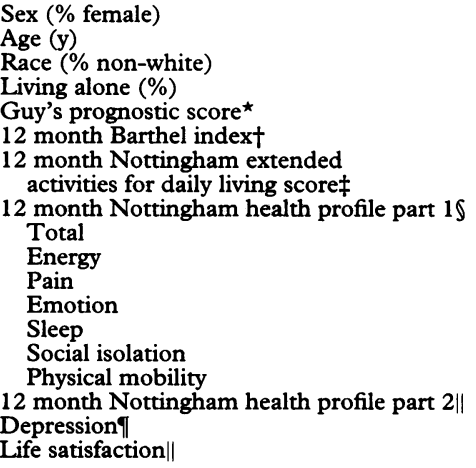 & $\begin{array}{c}232 \\
61 \\
28 \\
33 \\
29 \\
30 \\
52 \\
2 \cdot 7 \\
8 \cdot 1 \\
4 \cdot 6\end{array}$ & $\begin{array}{c}217 \\
56 \\
23 \\
31 \\
29 \\
28 \\
52 \\
2 \cdot 5 \\
7 \cdot 3 \\
4 \cdot 2\end{array}$ & $\begin{array}{l}(81) \\
(81) \\
(81) \\
(81) \\
(81) \\
(64)\end{array}$ \\
\hline
\end{tabular}

Possible ranges: ${ }^{\star}$ roughly -35 to $+35 ; \nmid 0-20 ; \ddagger 0-22$; Seach subscale $0-100 ; \| 0-7 ; 90-15$

Table 2 Distribution of responses for each handicap dimension

\begin{tabular}{lccclcc}
\hline Disadvantage & None & Slight & Moderate & Considerable & Severe & Extreme \\
\hline Mobility & $9(10)$ & $15(16)$ & $21(23)$ & $29(32)$ & $8(9)$ & $9(10)$ \\
Physical independence & $7(8)$ & $6(6)$ & $28(31)$ & $27(30)$ & $8(9)$ & $15(16)$ \\
Occupation & $4(4)$ & $13(14)$ & $4(4)$ & $16(17)$ & $27(29)$ & $28(30)$ \\
Social integration & $16(17)$ & $19(21)$ & $15(16)$ & $26(28)$ & $12(13)$ & $4(4)$ \\
Orientation & $22(23)$ & $25(27)$ & $21(23)$ & $14(15)$ & $9(19)$ & 0 \\
Economic self sufficiency & $8(9)$ & $30(32)$ & $7(7)$ & $33(35)$ & $14(15)$ & 0 \\
\hline
\end{tabular}

Figures in parentheses are \%.

London handicap scale with a letter of explanation inviting them to fill in the questionnaire. Non-responders were not sent reminders or followed up further as they had already received several mailings and further pressure was thought to be unfair. A sample of those who did respond were sent a second questionnaire about a fortnight later to examine test-retest reliability.

Data were entered into a computer for analysis, by SPSS/PC + . The association between scores on different scales was assessed by calculating Pearson's correlation coefficient. Reliability was assessed firstly by calculating the reliability coefficient (the proportion of total variance attributable to real variability after the removal of variance due to

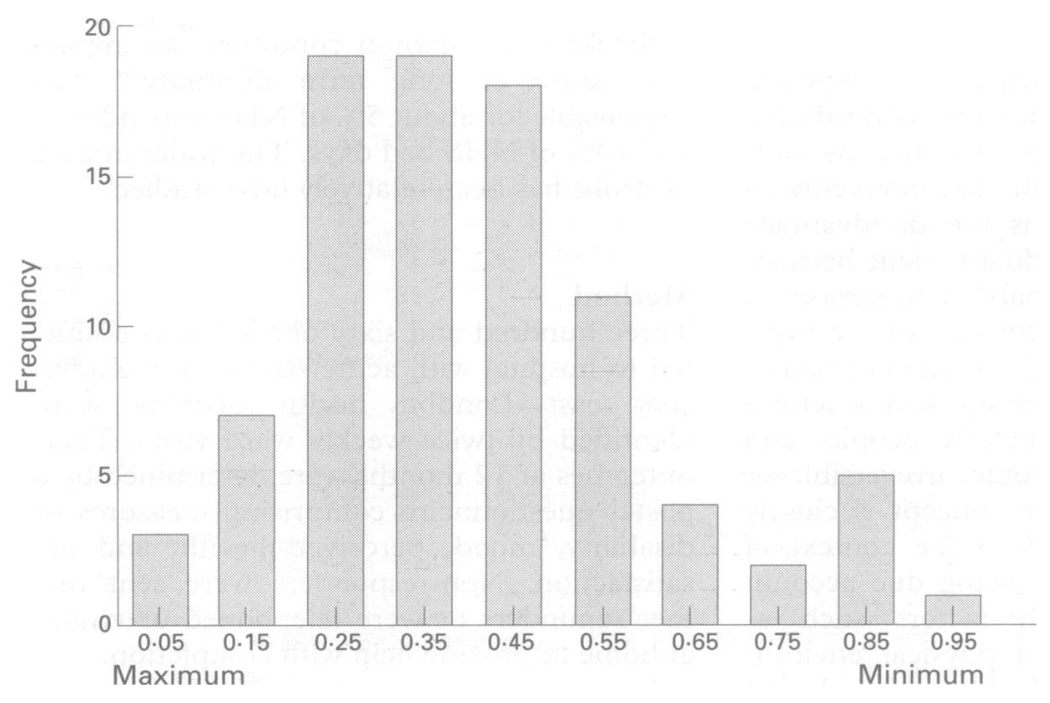

Figure 1 Distribution of handicap scores poor reliability), and secondly according to the method of Bland and Altman. ${ }^{13}$ Mean test-retest handicap score was plotted against test-retest difference to examine if unreliability were related to absolute score. Mean testretest difference was calculated to assess bias. The limits of agreement were calculated as the range within which $95 \%$ of retest scores were likely to fall (twice the SD of the test-retest difference).

\section{Results}

Of the 361 registered subjects, 170 (46\%) survived to 12 months. One hundred and forty one were sent the London handicap scale. Ninety four (67\%) replies were received, of which five were incomplete. Table 1 compares the age, race, living arrangements, and disability scores of the responders and non-responders (where these were available). Non-responders were more likely to be non-white, and had slightly more severe strokes judged by their mean Guy's prognostic score, ${ }^{14}$ and to be slightly more disabled on their mean Barthel and Nottingham extended activities of daily living scores, although Nottingham health profile, depression, and global life satisfaction scores were no worse than responders' scores.

Seventy one per cent received help to complete the questionnaire (spouse 19\%, child $27 \%$, professional $13 \%$, others $12 \%$ ). Table 2 shows the distribution of responses on each of the six dimensions. A wide range of disadvantages was revealed on each. The extreme disadvantage categories of orientation (unconscious) and economic self sufficiency (destitute) were not appropriate for this sample, and consequently were not chosen by any subject. Figure 1 shows the distribution of handicap scores derived by applying the matrix of scale weights to the questionnaire responses. The mean score was 0.40 (SD $0 \cdot 20$ ), range $0 \cdot 06-1 \cdot 0$.

\section{CONSTRUCT VALIDITY}

Table 3 shows correlation coefficients for the

Table 3 Correlations between handicap score and other outcome measurements

\begin{tabular}{lccc}
\hline Outcome & $\begin{array}{l}\text { Correlation } \\
\text { coefficient }\end{array}$ & $(n)$ & $p$ Value \\
\hline $\begin{array}{l}\text { Barthel index } \\
\text { Nottingham extended }\end{array}$ & 0.56 & $(88)$ & $<0.001$ \\
$\quad$ activities for daily & & & \\
living (total) & 0.69 & $(87)$ & $<0.001$ \\
Mobility & 0.66 & $(88)$ & $<0.001$ \\
Kitchen & 0.52 & $(88)$ & $<0.001$ \\
Domestic & 0.62 & $(88)$ & $<0.001$ \\
$\quad$ Leisure & 0.64 & $(87)$ & $<0.001$ \\
Nottingham health profile & & & \\
part 1 & & & \\
$\quad$ "Total" & -0.42 & $(82)$ & $<0.001$ \\
$\quad$ Physical mobility & -0.52 & $(82)$ & $<0.001$ \\
$\quad$ Energy & -0.36 & $(82)$ & $<0.001$ \\
$\quad \begin{array}{l}\text { Pain } \\
\text { Social isolation }\end{array}$ & -0.31 & $(82)$ & $<0.01$ \\
$\quad$ Emotion & -0.30 & $(82)$ & $<0.01$ \\
$\quad$ Sleep & -0.28 & $(82)$ & $<0.01$ \\
Nottingham health profile & -0.19 & $(82)$ & $<0.05$ \\
part 2 & -0.28 & $(83)$ & $<0.01$ \\
Geriatric depression score & -0.42 & $(81)$ & $<0.001$ \\
Life satisfaction & -0.36 & $(78)$ & $<0.001$ \\
\hline & & & \\
\hline
\end{tabular}




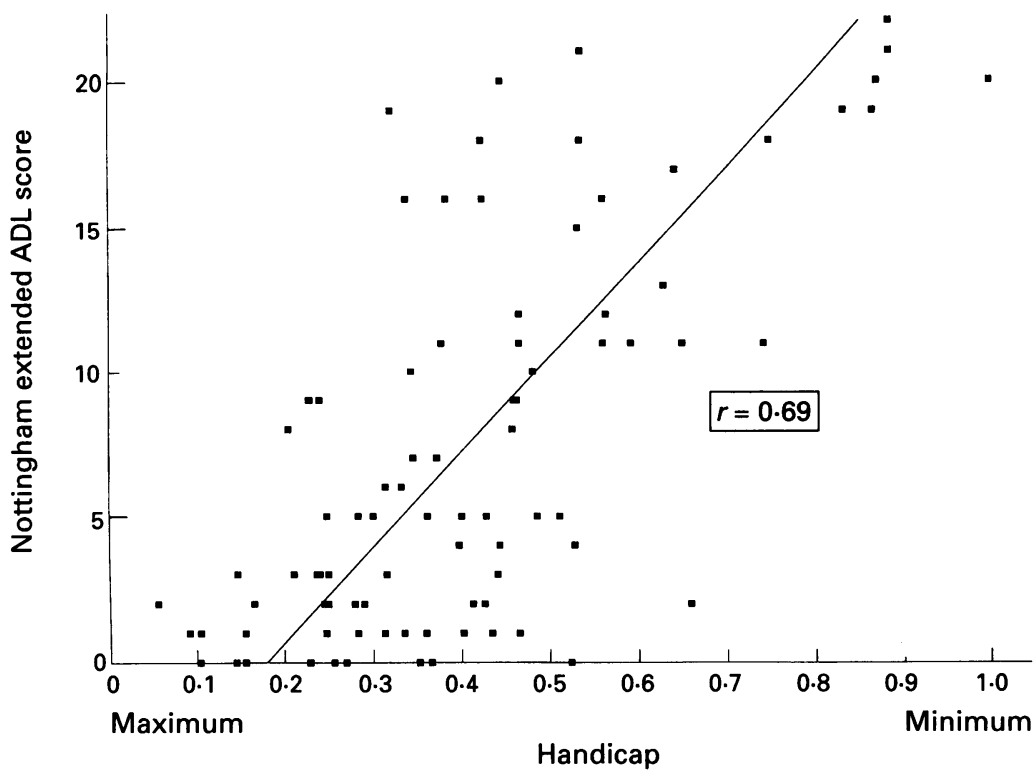

Figure 2 Relation between Nottingham extended activities of daily living (ADL) score and handicap. severities of disadvantage on each dimension. The classification questionnaire therefore seemed to be discriminating well between subjects. The only two categories that had no responses (extreme disadvantage on orientation and economic self sufficiency) represented unconsciousness and destitution respectively, for which responses would not be expected. Disadvantage in occupation, physi$\mathrm{cal}$ independence, and to a lesser extent mobility and economic self sufficiency were especially severe. Occupation disadvantage reflects an inability to occupy one's time in a manner appropriate to one's age, sex, and background. It includes work, leisure activities, and domestic tasks. Problems with occupation can easily be seen in any long stay hospital ward or residential home for elderly people. Fortunately, social, family, and other interventions (activities organisers, day centres, volunteer visitor schemes) can reduce this disadvantage even in the face of severe physical disability, and such interventions require evaluation. One of the advantages of the system of scale weights derived in the development of the London handicap scale is that problems on each dimension can be combined together to give an overall handicap score according to the importance attached to each activity (and different degrees of problems in those activities) by an unselected sample of the general public. This allows comparisons to be made between different diseases or combinations of diseases, and different types of therapeutic intervention.

Whether scales purporting to measure concepts that cannot be directly or definitively measured do actually measure these things depends on face validity and determination of construct validity. Face validity is based on the content and theoretical rationale of the scale, features that are strong in the London handicap scale. Construct validity is assessed from the performance of the scale in practice; whether it behaves as expected on the basis of "constructs" or hypotheses (such as, that more disabled subjects will, on average, be more handicapped).

In this study, the "constructs" being tested were that there was systematic variation of each outcome with handicap score, for which a statistically significant correlation is sufficient affirmation. All the correlations were in the expected directions. The strengths of the observed associations are limited by the fact that the scales are intended to measure different things; a perfect correlation implies that scores on one scale can be predicted perfectly by knowing the score on the other scale, hence no information is gained by using the new scale. The strongest correlation was with the Nottingham extended activities of daily living scale $\left(r^{2}=0.48\right.$, that is, half the variance in handicap scores can be explained by differences in extended activities of daily living scores), reflecting the importance of the items in that scale for overall handicap. The Barthel index was also strongly correlated $\left(r^{2}=0 \cdot 36\right)$. Although the Nottingham health profile was not originally designed to be summed across
There was a wide distribution of responses amongst categories representing different 
dimensions, a summary score obtained by doing this was correlated with $r^{2}=0 \cdot 19$. Limitations in the very basic activities in the Barthel index and the diverse collection of features in the Nottingham health profile were evidently perceived as causing less disadvantage. Another factor reducing the strength of association between patients' scores on different scales is that the method of weighting items in each scale (based on the opinions of a representative external population for the London handicap scale and Nottingham health profile, and on those of the originators for the others) has validity when making group comparisons, but is less valid for assessments in individual patients. Overall, the direction and strength of the correlations are consistent with the validity of the London handicap scale as a measure of handicap in a population of subjects one year after a stroke.

Test-retest reliability was reasonable compared with other subjective outcome measures. ${ }^{15}$ As there will always be a trade off between reliability and sensitivity to change, further work on the London handicap scale will focus on improving reliability and making assessments of sensitivity to change (such as measuring "effect size"). ${ }^{16}$ Mean test-retest difference over a group of patients was negligible (the mean retest score was the same as the mean test score on the same subjects). Because the scale is designed for the assessment of groups rather than individual patients, this result is important, indicating that group repeatability is excellent. The variability between repeated measures on the individual subjects merely makes it harder to exclude chance as the explanation of an observed change when performing statistical hypothesis testing, thus making the London handicap scale a conservative outcome measure.

In rehabilitation, handicap has important theoretical advantages as an outcome measure. By concentrating on the habitual abilities and limitations on someone's life, given their own particular circumstances (for example their physical environment, wealth, relationships, and availability of aids and equipment), handicap gives a relevant description of the needs for and effectiveness of health and other services. The effects of disease, medical and rehabilitation therapy, environmental adaptations, formal and informal help, and psychological state are integrated in descriptions of handicap. In many rehabilitation interventions the impact of disease is reduced without affecting disability; in this situation handicap must be used to measure outcomes. For example, the reason for someone being housebound will not depend solely on disabilities (such as the ability to walk), but also on access, the availability of help, and confidence. Similarly the ability to keep oneself occupied may depend crucially on statutory services (such as day care) or the availability of an informal carer. From the point of view of resources, ill health may diminish the opportunities for earning a living, whereas plentiful resources may allow some disadvantages to be overcome (such as improving mobility by owning a car, equipping the house with labour saving devices, or buying private nursing care). The requirement for help (human or otherwise and beyond what is normally expected) with basic needs or for improving the overall quality of life is, of course, a disadvantage in itself, and is subsumed under the category of physical independence handicap.

Despite these advantages, measurement of handicap has proved difficult, not least because of the difficulties in making measurements where the impact of problems is very different for different patients, who have different past achievements, aspirations, and reasons for living. We have used a technique for deriving scale weights that aggregated values from a sample of a representative population. Consequently the London handicap scale has validity only for making measurements in groups, rather than individual patients; although this is all that is required for most epidemiological and public health purposes (such as clinical trials, needs assessment, audit, and casemix adjustment). The London handicap scale proved acceptable to subjects, easy to administer, and should prove a useful addition to the range of available outcome measures. The measurements showed substantial handicap one year after a stroke, reflecting considerable unmet rehabilitation needs.

Rowan Harwood is a Medical Research Council training fellow. Patrick Gompertz was supported by North East Thames Regional Health Authority. Pandora Pound collected follow up data and was supported by the Royal College of Physicians of London.

Appendix: the London handicap scale YOUR HEALTH AND YOUR LIFE

This questionnaire asks six questions about your everyday life. Please answer each question. Tick the box next to the sentence which describes you best. Think about things you have done over the last week. Compare what you can do with what someone like you who is in good health can do.

\section{Getting around [mobility]}

Think about how you get from one place to another, using any help, aids or means of transport that you normally have available.

Does your health stop you from getting around?

1. Not at all: You go everywhere you want to, no matter how far away.

2. Very slightly: You go most places you want to, but not all.

3. Quite a lot: You get out of the house, but not far away from it.

4. Very much: You don't go outside, but you can move around from room to room indoors.

5. Almost completely: You are confined to a single room, but can move around in it.

6. Completely: You are confined to a bed or a chair. You cannot move around at all. There is no one to move you.

Looking after yourself [physical independence] Think about things like housework, shopping, looking after money, cooking, laundry, getting dressed, washing, shaving and using the toilet.

Does your health stop you looking after yourself?

1. Not at all: You can do everything yourself. 
2. Very slightly: Now and again you need a little help.

3. Quite a lot: You need help with some tasks (such as heavy housework or shopping), but no more than once a day.

4. Very much: You can do some things but you need help more than once a day. You can be left alone safely for a few hours.

5. Almost completely: You need help to be available all the time. You cannot be left alone safely.

6. Completely: You need help with everything. You need constant attention, day and night.

Work and leisure [occupation]

Think about things like work (paid or not), housework, gardening, sports, hobbies, going out with friends, travelling, reading, looking after children, watching television and going on holiday.

Does your health limit your work or leisure activities?

1. Not at all: You can do everything you want to do.

2. Very slightly: You can do almost all the things you want to do.

3. Quite a lot: You find something to do almost all the time, but cannot do some things for as long as you would like.

4. Very much: You are unable to do a lot of things, but can find something to do most of the time.

5. Almost completely: You are unable to do most things, but can find something to do some of the time.

6. Completely: You sit all day doing nothing. You cannot keep yourself busy or take part in any activities.

Getting on with people [social integration]

Think about family, friends and people you might meet during a normal day

Does your health stop you getting on with people?

1. Not at all: You get on well with people, see everyone you want to see, and meet new people.

2. Very slightly: You get on well with people, but your social life is slightly limited.

3. Quite a lot: You are fine with people you know well, but you feel uncomfortable with strangers.

4. Very much: You are fine with people you know well, but you have few friends and little contact with neighbours. Dealing with strangers is very hard.

5. Almost completely: Apart from the person who looks after you, you see no one. You have no friends and no visitors.

6. Completely: You don't get on with anyone, not even people who look after you.

Awareness of your surroundings [orientation]

Think about taking in and understanding the world around you, and finding your way around in it.

Does your health stop you understanding the world around you?

1. Not at all: You fully understand the world around you. You see, hear, speak, and think clearly, and your memory is good.

Table A1 Appendix: table of scale weights

\begin{tabular}{|c|c|c|c|c|c|c|}
\hline & \multicolumn{6}{|c|}{ Scale weight $\left(u_{i}\right)$ for level of disadvantage } \\
\hline & 1 & 2 & 3 & 4 & 5 & 6 \\
\hline $\begin{array}{l}\text { Mobility (m) } \\
\text { Physical }\end{array}$ & $0 \cdot 071$ & $0 \cdot 038$ & 0.000 & -0.036 & $-0 \cdot 072$ & $-0 \cdot 108$ \\
\hline $\begin{array}{l}\quad \text { independence (pi) } \\
\text { Occupation (oc) } \\
\text { Social integration (si) } \\
\text { Orientation (or) } \\
\text { Economic self } \\
\quad \text { sufficiency (ess) }\end{array}$ & $\begin{array}{l}0.102 \\
0.099 \\
0.063 \\
0 \cdot 109 \\
0 \cdot 100\end{array}$ & $\begin{array}{r}0.011 \\
-0.004 \\
0.035 \\
-0.008 \\
0.067\end{array}$ & $\begin{array}{r}-0.021 \\
-0.014 \\
0.007 \\
-0.038 \\
0.033\end{array}$ & $\begin{array}{l}-0.053 \\
-0.024 \\
-0.022 \\
-0.051 \\
-0.023\end{array}$ & $\begin{array}{l}-0.057 \\
-0.035 \\
-0.029 \\
-0.063 \\
-0.067\end{array}$ & $\begin{array}{l}-0.061 \\
-0.060 \\
-0.041 \\
-0.075 \\
-0.111\end{array}$ \\
\hline
\end{tabular}

2. Very slightly: You have problems with hearing, speaking, seeing or your memory, but these do not stop you doing most things.

3. Quite a lot: You have problems with hearing, speaking, seeing, or your memory, which make life difficult a lot of the time. But, you understand what is going on

4. Very much: You have great difficulty understanding what is going on.

5. Almost completely: You are unable to tell where you are or what day it is. You cannot look after yourself at all.

6. Completely: You are unconscious, completely unaware of anything going on around you.

Affording the things you need [economic selfsufficiency]

Think about whether health problems have led to any extra expenses, or have caused you to earn less than you would if you were healthy.

Are you able to afford the things you need?

1. Yes, easily: You can afford everything you need. You have easily enough money to buy modern laboursaving devices, and anything you may need because of ill-health.

2. Fairly easily: You have just about enough money. It is fairly easy to cope with expenses caused by illhealth.

3. Just about: You are less well-off than other people like you; however, with sacrifices you can get by withou help.

4. Not really: You only have enough money to meet your basic needs. You are dependent on state benefits for any extra expenses you have because of ill-health.

5. No: You are dependent on state benefits, or money from other people or charities. You cannot afford things you need.

6. Absolutely not: You have no money at all and no state benefits. You are totally dependent on charity for your most basic needs.

1 World Health Organization. International classification of impairments, disabilities and handicaps. Geneva: WHO, 1980.

2 Ebrahim, S. Measurement of impairment, disability and handicap. In: Hopkins A, Costain D, ed. Measuring the outcomes of medical care. London: Royal College of Physicians of London, 1990:27-41.

3 Churchill GA. Marketing research: methodological foundations. 3rd edition. Chicago: Dryden Press, 1989:278-85.

4 SPSS Categories. Chicago: SPSS, 1990.

5 Mahoney FI, Barthel DW. Functional evaluation: the Barthel index. Md State Med $\mathcal{F} 1965 ; 14: 61-5$.

6 Nouri FM, Lincoln NB. An extended activities of daily living index for stroke patients. Clin Rehab 1987;1:301-5.

7 Hunt SM, McEwan J, McKenna SP. Measuring health status. London: Croom Helm, 1986.

8 Yesavage JA. Geriatric depression scale. Psychopharmacol Bull 1988;24:709-11.

9 Alden D, Austin C, Sturgeon R. A correlation between the geriatric depression scale long and short forms. $\mathcal{F}$ Gerontol 1989;44:124-5.

10 McDowell I, Newell C. Measuring health: a guide to rating scales and questionnaires. New York: Oxford University scales and questionn

11 Martin J, Melzer H, Eliot D. The prevalence of disability among adults. OPCS social survey division. London: HMSO, 1988 .

12 Seale C, Davies $P$. Outcome measurement in stroke rehabilitation research. Int Disabil Stud 1987;9:155-60.

13 Bland JM, Altman DG. Statistical methods for assessing agreement between two methods of clinical measurement. Lancet 1986;1:307-10.

14 Allen CMC. Predicting the outcome of acute stroke: a prognostic score. F Neurol Neurosurg Psychiatry 1984;47: 475-80.

15 Gompertz PH, Pound P, Ebrahim S. The reliability of stroke outcome measurements. Clin Rehab 1993;7: 290-6.

16 Fitzpatrick R, Ziebland S, Jenkinson C, Mowat A, Mowat A. Importance of sensitivity to change as a criterion for selecting health status measures. Oual Health Care 1992;1:89-93. 